\title{
Assistência jurídica gratuita: serviços da Defensoria Pública da União na ótica da abordagem integradora da inovação
}

Bernardo Oliveira Buta

Universidade de Brasília (UnB)

Antonio Isidro Silva Filho

Universidade de Brasilia (UnB)

Com o objetivo de identificar as características dos serviços da Defensoria Pública da União, a partir da abordagem integradora da inovação, realizou-se um estudo de caso qualitativo-descritivo. Observou-se que, para a prestação de assistência jurídica, é necessário mobilizar competências relacionadas ao conhecimento e operação do Direito, atendimento ao público, interação com outros órgãos, realização de mutirões e conciliação extrajudicial. Os serviços são construídos por meio de operações informacionais, de conhecimento e relacionais. Modificações nas competências e nos meios de construção conduziram principalmente inovações incrementais e de melhoria, ligadas ao princípio norteador intensivo. Observou-se também a relação entre princípios norteadores e formas de inovação, sendo o princípio extensivo ligado à forma radical, o intensivo relacionado às formas incremental e de melhoria, e o combinatório orientador das formas ad hoc e por recombinação.

Palavras-chave: serviço públicos, Defensoria Pública, inovação 
Asistencia jurídica gratuita: servicios de la Defensoría Pública de la Unión desde la perspectiva del enfoque integrado para la innovación

Con el objetivo de identificar las características de los servicios de la Defensoría Pública de la Unión en Brasil, desde la perspectiva del abordaje integradora de la innovación, se llevó a cabo un estudio de caso cualitativo-descriptivo. Se observó que, para la prestación de asistencia jurídica, es necesario movilizar competencias relacionados con el conocimiento y la operación del Derecho, el servicio al cliente, la interacción con otros organismos, la realización de esfuerzos conjuntos y la conciliación extrajudicial. Los servicios se construyen por medio de operaciones informacionales, relacionales y de conocimiento. Los cambios en las competencias y en los medios de construcción llevaron a innovaciones de mejoría e incrementales, principalmente vinculadas al principio rector intensivo. También se ha observado la relación entre los principios rectores y las formas de innovación, con el principio extensivo vinculado a la forma de innovación radical, el intensivo relacionado con las formas incrementales y de mejoría, el principio combinatorio vinculado a las formas de innovación ad hoc y de recombinación.

Palabras-clave: servicios públicos, Defensoría Pública, innovación

Free legal assistance: services of the Brazilian Federal Public Defender's Office in the perspective of innovation integrative approach

A qualitative-descriptive case study on the perspective of the innovation integrative approach was realized to identify the services characteristics of the brazilian Federal Public Defender's Office. The results show that it is necessary to mobilize competencies related to the knowledge and operation of the Law, customer services, integration with other public agencies, joint efforts, and extrajudicial conciliation, in order to delivery juridical assistance. The services are composed by informational operations, methodological operations, and relational service operations. Changes in the competences mobilized, and in the services operations lead mainly to improvement and incremental innovations, both connected to the intensive organizing principle. It was also seen the relationship between innovation organizing principles and modes of innovation. The extensive organizing principle is connected to the radical innovation, intensive organizing principle is related to both incremental and improvement modes of innovation, and the combinatory principle is associated to the $\mathrm{ad}$ hoc and recombinative modes of innovation.

Keywords: public services, Public Defense, innovation 


\section{Introdução}

A reforma constitucional no Sistema de Justiça, iniciada com a promulgação da Emenda Constitucional no 45, de dezembro de 2004, tem permitido o aprimoramento da gestão nas organizações da Justiça. Tal reforma motivou dois pactos firmados pelos três Poderes do Estado brasileiro que ressaltam a importância do aprimoramento dos serviços prestados pelas organizações do Sistema de Justiça. Trata-se do Pacto de Estado em Favor de um Judiciário mais Rápido e Republicano (BRASIL, 2004), e do Pacto Republicano por um Sistema de Justiça mais Acessível, Ágil e Efetivo (BRASIL, 2009).

Nos últimos anos, essa reforma contou com dois importantes passos: a autonomia da Defensoria Pública da União (DPU) e a determinação constitucional de expansão do acesso à Justiça. Em relação à DPU, a Emenda Constitucional no 74, de 2013, conferiu a esse órgão autonomia administrativa e funcional, bem como a iniciativa de sua proposta orçamentária. Ademais, a Emenda Constitucional no 80, de 2014, determina a expansão da Defensoria Pública no Brasil, atribuindo prazo de oito anos para que haja defensores públicos em todas as unidades jurisdicionais do País.

Tais acontecimentos demonstram a relevância alcançada pelas organizações da Justiça, e especificamente pela Defensoria Pública. Nesse contexto, a intenção deste trabalho é conhecer metodologicamente os serviços prestados pela DPU, os quais passam por um processo de aprimoramento para a universalização exigida constitucionalmente. Assim, o desenvolvimento desta pesquisa se pauta pelo seguinte problema: quais são as características dos serviços da Defensoria Pública da União, com base na abordagem integradora da inovação?

Considerando o problema apresentado, o objetivo geral do trabalho é identificar as características dos serviços da DPU sob a ótica da abordagem integradora da inovação. Para atingir esse objetivo geral, é necessário contemplar os seguintes objetivos específicos: 1) identificar os serviços principais, bem como os serviços constituintes da Defensoria Pública da União; 2) identificar as operações do serviço de assistência jurídica na DPU; 3) identificar as inovações nos serviços a partir da abordagem integradora da inovação.

Oportunamente, destaca-se que o presente trabalho se coaduna com outras agendas de pesquisa. Maciel e Koerner (2002) salientam a necessidade de se avaliar o papel das instituições judiciais e de sua dinâmica organizacional nas recentes transformações ocorridas no Estado brasileiro. Além disso, Isidro-Filho, Guimarães e Perin (2012) indicam a importância de se estudar o impacto de inovações na qualidade dos serviços percebida pelos usuários. Igualmente, Resende, Guimarães e Bilhim (2013) sugerem o estudo das motivações para se inovar no setor público. 
Por fim, há escassez de estudos sobre inovação no setor público, segundo Halvorsen et al. (2005).

Essa percepção é compartilhada por Brandão e Bruno-Faria (2012), que, ao realizarem uma revisão bibliográfica sobre inovação no setor público, encontraram apenas 30 artigos publicados nos últimos 10 anos, sendo 23 em periódicos internacionais e somente sete em periódicos nacionais.

\section{Abordagem integradora da inovação e o contexto de serviços}

Uma vez que se está tratando sobre a descrição de serviços, é importante prover significado a esse termo. Serviços são comumente definidos com base em critérios técnicos, derivados da economia clássica, ou sociotécnicos, referentes às relações sociais e econômicas. Acerca da definição baseada em critérios técnicos, os serviços são tidos como produtos imateriais e efêmeros, extinguindose no momento de sua produção, além de serem resultado de coprodução entre o prestador do serviço e o usuário, bem como não poderem ser estocados ou transportados. Já no que se refere aos critérios sociotécnicos, os serviços são entendidos como situações ou relacionamentos que giram em torno de procedimentos capazes de gerarem mudanças na condição de uma entidade detentora da realidade a ser transformada (GADREY, 2000).

Há dois pontos-chave no conceito de serviços: (1) mudança na condição de uma pessoa ou de um bem com a concordância mútua das pessoas interessadas; e (2) mudança como um resultado da atividade de outra pessoa. Nesse contexto, um serviço pode ser definido como mudança na condição de uma pessoa [B], ou de um bem [C] pertencente a essa pessoa, que ocorre como resultado da atividade de outra pessoa [A], com a concordância prévia da primeira (HILL, 1977).

Os serviços podem ser tangíveis, permanentes, não relacionais, e passíveis de serem estocados ou prestados a distância. Serviços podem ser, portanto, qualquer aquisição por um agente [B] (indivíduo ou organização) dos direitos de uso de uma capacidade técnica ou humana possuída ou controlada por outro agente [A]. Tal transação dar-se-ia possivelmente por um período de tempo específico e de modo a produzir efeitos úteis no agente [B] ou nos bens [C] de posse ou sob a responsabilidade de [B] (GADREY, 2000).

Considerando as contribuições de Gadrey (2000) e Hill (1977), serviços podem ser graficamente representados por um triângulo $A B C$, no qual o vértice $[A]$ representa o agente prestador do serviço, o [B] representa o agente usuário e o vértice $[C]$ representa os bens de posse ou sob a responsabilidade de $[B]$, nos quais o serviço pode ser prestado. Assim, a produção econômica dos serviços se dá na 
relação entre o prestador e o usuário do serviço, podendo ser direta ou incidente sobre um bem ou meio controlado pelo usuário.

A abordagem de Hill (1977) e Gadrey (2000) é tida como orientada aos serviços, pois os define de forma separada do conceito de bens. Já Gallouj e Weinstein (1997) buscam uma definição genérica, representando tanto bens quanto serviços. Por meio dessa perspectiva de análise, a provisão de qualquer tipo de produto (bens ou serviços) pode ser descrita em termos de uma série de características, as quais refletem a estrutura interna do produto em questão, suas propriedades externas, as características técnicas, assim como os conhecimentos e competências do fornecedor e do usuário mobilizadas para sua produção.

Assim, as características dos produtos podem ser descritas por meio de vetores, desenvolvendo o triângulo de serviços. O vetor [Y] representa as características finais do produto, ou seja, aquelas características vistas da perspectiva do usuário; o vetor $[\mathrm{X}]$, as características internas ou técnicas do bem ou serviço, trata-se das características de mecanismos técnicos utilizados na obtenção das características finais; o vetor [C] representa as competências mobilizadas pelo produtor do bem ou prestador do serviço; e o vetor [ $\left.C^{\prime}\right]$ representa as competências do usuário mobilizadas na coprodução do bem ou serviço (GALLOUJ; WEINSTEIN, 1997).

Desse modo, um produto pode ser representado por um conjunto de características finais [Yi]. Cada Yi indica o nível de uma característica "i" na composição desse produto. As características finais são obtidas por meio da combinação de características técnicas [Xj], sendo cada característica final [Yi] obtida por certo subconjunto de técnicas $[\mathrm{Xj}]$. De modo similar, cada característica técnica mobiliza as competências [Ck] e/ou [ $C^{\prime} k$ ]. Em certas situações, essas mesmas competências devem ser mobilizadas diretamente (GALLOUJ; WEINSTEIN, 1997). Esse modelo pode ser visualizado na Figura 1.

Figura 1 - Representação geral do produto (bens e serviços)

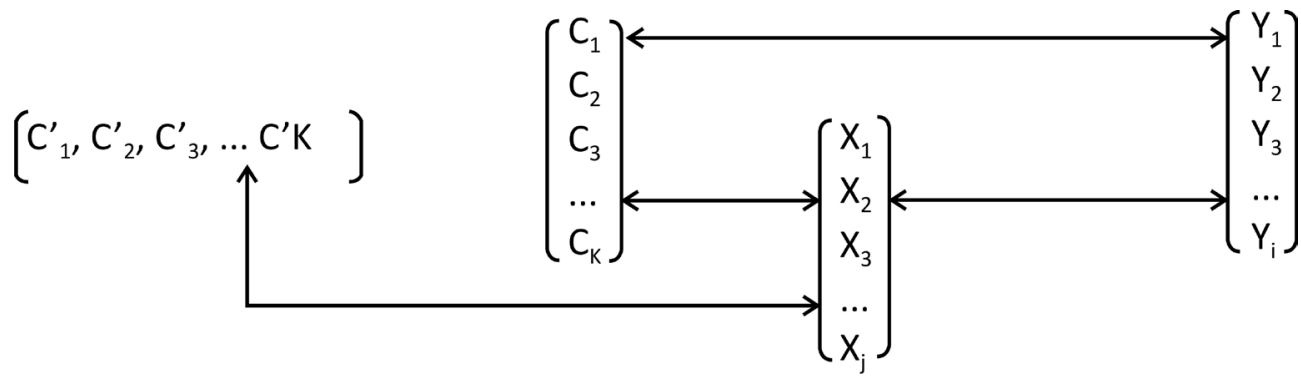

Fonte: Gallouj e Weinstein (1997). 
Há diversos modelos ou abordagens ligados ao fenômeno da inovação em serviços. Sobre o assunto, Gallouj e Savona (2009) realizaram uma revisão bibliográfica, indicando três abordagens da literatura acerca do tema inovação em serviços. As duas primeiras podem ser entendidas como opostas. Por um lado, a abordagem tecnicista reduz a inovação à simples adoção e uso de tecnologia. As contribuições alinhadas a essa abordagem tentam assimilar os serviços com um modelo já consolidado utilizado para setores da indústria. Por outro lado, a abordagem orientada aos serviços busca desenvolver um modelo específico para a inovação em serviços, enquanto se esforça por destacar todas as especificidades em produtos de serviços e nos processos produtivos (GALLOUJ; SAVONA, 2009).

A terceira abordagem é tida como integradora, pois desenvolve um modelo conceitual comum, tomando por ponto de partida as convergências entre bens e serviços. Tal modelo busca explicar a inovação por meio de uma visão mais ampla, aplicável para qualquer produto tangível ou intangível. Diferentemente das abordagens tecnicista e orientada aos serviços, essa última abordagem é baseada em uma nova definição de produto. Segundo a perspectiva integradora, o fenômeno da inovação pode ser entendido como um processo de mudanças nas características dos produtos. Ou seja, mudanças em uma ou mais características definem a inovação, e o tipo de inovação varia conforme o mecanismo de variação dessas características (GAllouj; SAvonA, 2009).

Desse modo, o processo de inovação pode se dar por meio de evolução, variação, desaparecimento, associação e dissociação das características dos produtos. Esses mecanismos podem ser programados intencionalmente, ou podem ser emergentes (GAllouj; WeInStein, 1997). A combinação desses mecanismos torna possível diversas formas de inovação: (1) inovação radical, quando se cria um novo produto com características distintas de qualquer produto anterior, nesse caso, todo o sistema $\left\{\left[\mathrm{C}^{\prime}\right],[\mathrm{C}],[\mathrm{X}],[\mathrm{Y}]\right\}$ é transformado ou um novo sistema $\left\{\left[\mathrm{C}^{*}\right],\left[\mathrm{C}^{*}\right],\left[\mathrm{X}^{*}\right]\right.$, $\left.\left[\mathrm{Y}^{*}\right]\right\}$ é criado; (2) inovação de melhoria, que se dá por meio da simples melhoria de certas características ou competências; (3) inovação incremental, quando a estrutura geral do sistema $\left\{\left[\mathrm{C}^{\prime}\right],[\mathrm{C}],[\mathrm{X}],[\mathrm{Y}]\right\}$ é mantida, mas ocorre uma modificação marginal pela adição de novos elementos ao [X] e/ou ao [Y], ou pela substituição de elementos; (4) inovação ad hoc, quando há uma construção interativa de uma solução original para um problema particular de um dado cliente; (5) inovação de formalização, caso em que não há variação nas características finais ou técnicas dos produtos, apenas a maior visibilidade e padronização de um sistema já existente; (6) inovação por recombinação, que se dá por meio de novas combinações de diversas características finais e técnicas, tais combinações advêm do conhecimento estabelecido sobre o sistema ou sobre a base tecnológica do produto (GALLOUJ; WEINSTEIN, 1997). 
Djellal e Gallouj (2005) desenvolveram um modelo analítico que permite o entendimento do processo de inovação em toda sua diversidade. Tal modelo pauta-se no desenvolvimento daquelas características dos produtos apresentadas por Gallouj e Weinstein (1997). Com efeito, o modelo de Djellal e Gallouj (2005) abre o vetor $[\mathrm{X}]$ em grupos de operações que são combinados em diferentes proporções para formar as partes constituintes do serviço. Assim, são quatro as operações por meio das quais se constroem os produtos: material [M], que se refere às transformações operacionais logísticas ou materiais; informacional [I], relacionada à coleta e processamento de informações; conhecimento [K], referente ao processamento intelectual do conhecimento; e relacional $[R]$, relativa à interação com o usuário ou com os demais autores envolvidos na construção do produto.

Para capturar a inovação em sua completude, os autores sugerem a descrição dos produtos, levando-se em conta seus diversos fatores constituintes. Com esse intuito, o Quadro 1 apresenta um esquema funcional de análise de qualquer produto, seja bem ou serviço.

\section{Quadro 1 - Esquema funcional da análise dos produtos de bens ou serviços}

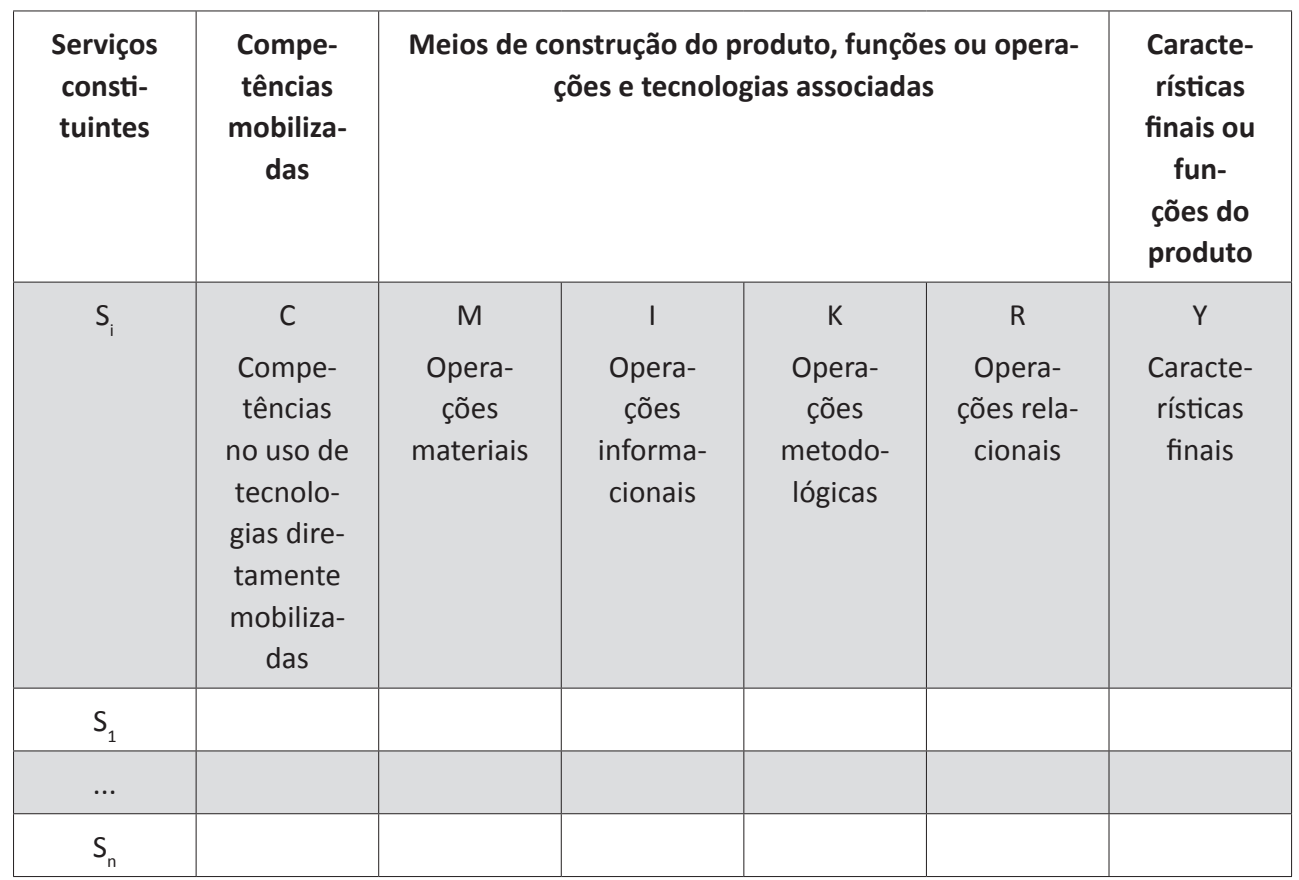

Fonte: Djellal e Gallouj (2005).

No Quadro 1,é possível observar o cerne do modelo analítico proposto por Djellal e Gallouj (2005). Os produtos ou serviços constituintes [Si] são aqueles que compõem os produtos finais do negócio. As competências [C] são aquelas mobilizadas para a 
construção ou entrega do produto, que podem ser técnicas e científicas, relacionais, criativas e operacionais. Os meios de construção, ou de entrega, do produto [M, I, R, K] são as operações materiais, informacionais, metodológicas, relacionais e de conhecimento, bem como os procedimentos científicos e tecnológicos a elas associados. As características finais [Y] referem-se ao uso final do produto, e são consideradas do ponto de vista do usuário. Essas características finais são geradas a partir da combinação das competências $[C]$ com os componentes técnicos $[M, I, R$, K] (DJellal; Gallouj, 2005).

Todas essas variáveis devem ser avaliadas para identificar as inovações. Assim, há alguns princípios norteadores da inovação, quais sejam: (1) extensivo, quando serviços constituintes são adicionados ao principal; (2) regressivo, que envolve a eliminação de serviços constituintes; (3) intensivo, o qual envolve uma mudança em um ou vários componentes internos ou externos do produto final, o que pode se dar pela adição de novas competências e/ou tecnologias, por sua redução ou pela transformação de competências ou tecnologias existentes em elementos mais significativos; e (4) combinatório, por meio do qual diferentes características dos serviços são combinadas para a constituição de novos serviços (DJELLAL; GALLOUJ, 2005).

Depois da definição dos significados de serviços e de inovação em serviços, o passo seguinte é incorporar a dimensão pública no escopo desses significantes. Sobre o assunto, Di Pietro (2010) define os serviços públicos baseando-se em três critérios: são atividades cujo objeto está na satisfação de necessidades coletivas; são atribuídos ao Estado por meio de lei, desse modo sua execução é de responsabilidade estatal, podendo ser realizada diretamente ou por meio de concessão ou permissão de sua prestação por particulares; e sua prestação, mesmo que realizada por particulares, está sujeita ao regime jurídico de Direito Público.

Destarte, os serviços públicos visam à garantia dos direitos dos cidadãos, que se dá por meio da prestação positiva do Estado ou de ente autorizado a fazêlo. Ou seja, trata-se da aplicação de competências do poder público, agindo direta ou indiretamente, para a promoção de direitos aos cidadãos. Portanto, a garantia dos direitos está intrinsecamente ligada à prestação de serviços públicos (DI PIETRO, 2010).

Desse modo, o que está sendo enfatizado no caso dos serviços públicos é que o agente prestador do serviço deve ser o Estado ou particular autorizado a fazêlo. A diferença em relação aos serviços prestados por particulares é a de que o Estado possui prerrogativas e deveres diferenciados. Como cita Bandeira de Mello (2007), o Estado não pode omitir-se ao dever de prestação dos serviços públicos 
e deve pautar suas decisões em razão da conveniência da coletividade, evitando discriminação entre os usuários e a interrupção na prestação dos serviços.

Apesar das prerrogativas e deveres do Estado na prestação dos serviços públicos, a ênfase no ente prestador do serviço não importa prejuízo para a análise baseada na abordagem integradora da inovação. De fato, Djellal, Gallouj e Miles (2013) demonstram que as perspectivas dominantes dos estudos de inovação negligenciam os serviços públicos, mas a abordagem integradora, por prover um quadro analítico capaz de envolver as dinâmicas de inovação em todas suas formas (tecnológicas, não tecnológicas, bens e serviços), pode ser facilmente estendida aos serviços públicos. Com efeito, a utilização da abordagem integradora para o estudo da inovação em serviços públicos não resta prejudicada pelo fato de o Estado exercer o papel de prestador do serviço. Na verdade, o modelo analítico de Djellal e Gallouj (2005) foi construído a partir de estudos sobre um tipo de serviço que é essencialmente público, o serviço de saúde.

Acerca do estudo da inovação em organizações da Justiça, cumpre destacar que o construto tem sido abordado principalmente sob o aspecto político-legal, caso em que a inovação é considerada a partir da perspectiva normativa, bem como de métodos e procedimentos jurídicos, de acesso ao Judiciário, e da difusão de inovações jurídicas. Esse construto tem sido abordado também em suas dimensões organizacional e gerencial, e tecnológica (SOUSA; GUIMARÃES, 2014). Especificamente sobre a Defensoria Pública, observou-se a abordagem da inovação sob uma perspectiva institucional histórica (D'ARAUJO, 2001; MADEIRA, 2014).

É forçoso ressaltar que o serviço de assistência jurídica é essencialmente intensivo em conhecimento, e serviços dessa natureza mostram-se particularmente sensíveis à inovação. Com efeito, as formas pelas quais a inovação é conduzida têm sido negligenciadas, ou até mesmo escondidas, mas podem ser identificadas por meio do foco nas atividades dos serviços (DJelLaL; GALlouj; MILES, 2013).

\section{Método e técnicas de pesquisa}

Esta pesquisa é um estudo de caso de natureza qualitativo-descritiva que traça as características dos serviços da DPU e destaca suas inovações. A natureza descritiva advém do intuito de delinear as características dos serviços de assistência jurídica, identificando, a partir daí, a inovação. A pesquisa foi realizada de modo transversal entre os meses de abril e junho de 2014, com um delineamento observacional estruturado, realizado por meio de pesquisa documental e levantamento de opiniões desenhado segundo orientações de Fowler (2011). 
Para a realização das entrevistas, os participantes foram selecionados intencionalmente. Foram escolhidos defensores públicos federais, bem como alguns servidores não defensores, que participam da alta administração da DPU, na qualidade de titulares de cargos-chave dentro do órgão. A escolha deveu-se ao fato de eles serem os formuladores das políticas da Defensoria, bem como terem uma visão mais abrangente acerca de sua atuação.

A média de tempo em que os participantes da pesquisa são servidores da DPU é de aproximadamente sete anos. Além disso, eles já participam da alta administração há, no mínimo, um ano e meio e, no máximo, sete anos, sendo o período médio de três anos e meio. A idade dos participantes varia de 29 a 39 anos, com a média de aproximadamente 36 anos.

Para se definir a alta administração da DPU, foi considerada a estrutura instituída pela Lei Complementar no 80/1994, que organiza a Defensoria Pública, prescrevendo normas gerais para sua organização, bem como suas alterações determinadas por meio da Lei Complementar no 132/2009. Ademais, utilizou-se também a estrutura formalizada pela Portaria DPGU no 88/2014, que dispõe sobre o Regimento Interno da Defensoria Pública-Geral da União.

Tomando-se por base esses normativos, as entrevistas foram levadas a cabo com a participação dos seguintes atores: Defensor Público-Geral Federal (DPGF), Subdefensor Público-Geral Federal (SubDPGF), Corregedor-Geral da Defensoria Pública da União (CGDPU), Secretário-Geral de Articulação Institucional (SGAI), Secretário-Geral de Controle Interno e Auditoria (SGCIA). No que se refere à Chefia de Gabinete, o cargo não estava provido quando da realização das entrevistas; no entanto, um dos participantes da pesquisa foi seu ocupante no período de 2012 a 2014. Acerca do Conselho Superior da DPU (CSDPU), três dos participantes da pesquisa são seus membros natos, a saber, o DPGF, o SubDPGF e o CGDPU. Não houve êxito no contato com o Diretor-Geral da Escola Superior da DPU, tampouco com a Secretária-Geral Executiva. Pode-se considerar, contudo, que a Escola Superior está representada, uma vez que um dos participantes da pesquisa foi seu Diretor-Geral no período de 2009 a 2011.

Além disso, alguns titulares de assessorias também participaram da pesquisa. Esses participantes foram escolhidos de acordo com as atribuições da assessoria que dirigem e sua capacidade de influenciar as decisões do DPGF. Desse modo, os atuais assessores-chefes que participaram da pesquisa são os titulares da Assessoria de Planejamento, Estratégia e Modernização da Gestão e da Assessoria de Comunicação Social. No entanto, outras assessorias estão representadas devido ao fato de os participantes da pesquisa já terem sido titulares da Assessoria Jurídica, Assessoria de Assuntos Legislativos, e Câmaras de Coordenação e Revisão. 
O instrumento utilizado para a realização das entrevistas foi o roteiro descrito a seguir. Sua construção teve como base o esquema funcional proposto por Djellal e Gallouj (2005), apresentado no Quadro 1.

1. Qual a sua idade e há quanto tempo você é Defensor Púbico Federal (ou servidor na DPU)?

2. Cargo que ocupa ou ocupou na alta administração da DPU?

3. Qual o período em que você participou da alta administração da DPU?

4. Em sua opinião, quais são os serviços prestados pela DPU?

No período em que você participou da alta administração, a DPU:

1. desenvolveu novos serviços para o cidadão? Quais foram os serviços desenvolvidos?

2. padronizou as características de seus serviços, tornando-os mais tangíveis para o cidadão? Tal formalização está definida em algum documento?

3. melhorou as características dos seus serviços? Quais foram as características modificadas?

4. combinou diferentes características dos serviços existentes para gerar novos serviços? De que forma?

5. ampliou ou suprimiu características dos serviços existentes? Quais características?

6. mudou e/ou introduziu novas formas de prestação dos serviços?

7. desenvolveu soluções específicas para problemas ou demandas particulares dos assistidos?

Ressalta-se que todas as entrevistas foram presenciais e tiveram gravação de áudio. A coleta resultou em um total de 2 h 52 min e 18 seg., cuja transcrição ocupou um total de 58 páginas. Após as entrevistas, o teor das informações obtidas foi analisado à luz do referencial teórico apresentado. Especificamente para a análise, as respostas dos participantes foram associadas à caracterização do serviço, conforme Djellal e Gallouj (2005), e às formas de inovação elencadas por Gallouj e Weinstein (1997). Analisaram-se os dados por meio de análise de conteúdo, na modalidade categorial, em conformidade com Bardin (2011).

A partir das narrativas dos participantes das entrevistas, foram identificados os serviços da DPU, suas características, bem como as formas de inovação e seus princípios organizadores. Os trechos que fazem referência aos itens que se pretendeu identificar foram recortados e organizados em uma tabela de análise. Após a identificação dos serviços e características, bem como das formas e princípios organizadores da inovação, os resultados foram cruzados com os documentos oficiais por meio dos quais tais itens estão formalizados. 


\section{Os serviços da Defensoria Pública da União}

A Constituição Federal, em seu art. 5ำ, LXXIV, estabelece como obrigação do Estado a prestação de assistência jurídica integral e gratuita àqueles que comprovarem insuficiência de recursos. A declaração desse direito gera ao Estado a obrigação de prestação do serviço de assistência jurídica de forma a garantir os direitos dos cidadãos. Para tanto, a própria Carta Constitucional, em seu art. 134, funda a Defensoria Pública como instituição permanente e essencial à função jurisdicional do Estado.

Sobre os serviços prestados pela DPU, sua Carta de Serviços (BRASIL, 2013) elenca as seguintes atividades: assistência judicial integral e gratuita, assistência extrajudicial para a resolução de conflitos e assistência jurídica preventiva e consultiva, todas elas voltadas à população carente. Sobre o assunto, a Lei Complementar no 80/1994 e a Lei Complementar n 132/2009, que a modificou em diversos pontos, também trazem uma série de orientações. Entre as funções institucionais elencadas, aquelas que podem ser entendidas como serviços são a defesa dos necessitados em todos os graus; a prestação de orientação jurídica; e a difusão e conscientização dos direitos humanos, da cidadania e do ordenamento jurídico.

Visando organizar essa miscelânea de informações acerca dos serviços da DPU, pode-se entender como serviço principal da Defensoria Pública da União a prestação de assistência jurídica às pessoas necessitadas. Isso foi unanimidade entre os participantes da pesquisa. Com efeito, alguns participantes elencaram certos serviços constituintes da DPU: orientação jurídica, defesa na esfera judicial, defesa extrajudicial, informação acerca de direitos e difusão de conhecimentos do ordenamento jurídico. Algumas falas ilustram bem isso.

A Defensoria presta assistência jurídica aos necessitados. Em algumas situações, aos necessitados jurídicos. Então, a Constituição estabelece que toda pessoa tem direito a assessoria jurídica... Esse é o serviço que basicamente a Defensoria presta. Pode ser a judiciária, que é a prestação do... de representar eles perante o Poder Judiciário, e pode ser também extrajudicial... questões administrativas, informação de direitos... é mais amplo que o mero jurídico (Entrevista 4).

Assistência jurídica está dividida em orientação jurídica, em defesa judicial, em defesa extrajudicial, defesa administrativa, em representação administrativa. Ela pode estar dividida em algumas coisas assim (Entrevista 3).

De fato, a prestação de assistência jurídica é um serviço abrangente, que pode envolver a simples orientação em virtude de uma consulta dos cidadãos; a defesa jurídica, tanto na esfera judicial quanto na administrativa; a difusão de conhecimentos 
acerca de direitos; e a resolução de conflitos por meio de conciliação. Ademais, no que concerne à DPU, essa atuação se dá nas matérias relativas às Justiças Federal, do Trabalho, Eleitoral, Militar, Tribunais Superiores e instâncias administrativas da União, conforme o art. 14 da Lei Complementar no 80/1994.

Além disso, para a definição dos serviços, importa conhecer também seus usuários. O público-alvo desses serviços está bem delimitado na Resolução CSDPU no 85, de fevereiro de 2014. Com base nesse normativo, o público passível de assistência da DPU compreende as pessoas naturais integrantes de núcleo familiar cuja renda bruta seja inferior a três salários mínimos; e as pessoas jurídicas que não remunerem seus empregados com valores superiores a dois salários mínimos, não remunerem seus sócios com valores superiores a três salários mínimos e não possuam faturamento anual superior a 180 vezes o salário mínimo.

Em suma, a DPU presta o serviço de assistência jurídica aos necessitados. Esse pode ser dividido em quatro serviços constituintes: orientação jurídica, defesa nas esferas judicial e administrativa, difusão de conhecimentos sobre direitos, e resolução de conflitos por meio de conciliação. O usuário desses serviços pode ser, em resumo, pessoas naturais ou jurídicas economicamente necessitadas.

\section{Competências}

De um modo geral, as competências mobilizadas estão relacionadas ao domínio das áreas do conhecimento específicas do Direito. Trata-se das habilidades e conhecimento necessários ao cumprimento das funções institucionais elencadas no art. 4으 da Lei Complementar no 80/1994. Nas entrevistas, percebeu-se que a atuação da DPU é mais ampla do que o mero atendimento jurídico. A Defensoria deve ter também a habilidade de atender o público de modo transversal, comunicando-se com outros órgãos ou entidades, conforme ressalta um dos participantes da pesquisa:

[...] ao invés de atender aos assistidos somente na área jurídica, e desde que eu estava na 2a Categoria, alguns colegas tinham a ideia de "não, por que só na área jurídica? Porque não trazer o Sesc e o Senai pra fazer o que fizeram agora recentemente, de o assistido cortar o cabelo..." você ter uma ideia de assistência integral não só na área jurídica, mas como um todo. E a DPU já fazia isso um pouco com relação à questão previdenciária, que a gente anexava ou agregava à questão previdenciária algumas questões da saúde, mesmo não sendo necessariamente um viés jurídico que a DPU pudesse intervir, mas ela participava de alguma colaboração na área médica ou da área social com Cras $^{1}$ e com Creas $^{2}$ (Entrevista 1 ).

\footnotetext{
${ }^{1}$ Centro de Referência da Assistência Social - Ministério do Desenvolvimento Social e Combate à Fome.

${ }^{2}$ Centro de Referência Especializado de Assistência Social - Ministério do Desenvolvimento Social e Combate à Fome.
} 
Sobre a competência de realizar o atendimento de modo transversal, a Lei Complementar no 80/1994 institui, em seu art. 4ㅇ, IV, o atendimento interdisciplinar como função institucional da Defensoria Pública. Nesse sentido, os órgãos de atuação da DPU mais estruturados contam com profissionais das áreas de Sociologia, Antropologia, Serviço Social, Psicologia, Medicina, entre outras, para a realização desse tipo de atendimento. De fato, a importância dessas áreas profissionais interdisciplinares é citada nas entrevistas.

[...] algumas unidades possuem médicos, assistentes sociais, outras não. Por quê? Por que a gente depende de requisição de outros órgãos. Por exemplo, em Fortaleza, o assistido que procura a Defensoria já sai com um parecer social e já é encaminhado ao médico dentro da própria Defensoria, então a chance de êxito numa ação judicial dele é muito maior, porque só se entra com ação judicial quando há efetivamente a necessidade [...] (Entrevista 4).

Dando sequência, a capacidade de interação com outros órgãos públicos, com a finalidade de solucionar problemas gerados pelas políticas públicas destinadas às pessoas carentes, é outra competência necessária à prestação dos serviços da DPU. Essa interação com outros órgãos pode ser indutora de inovações, conforme destacam Djellal, Gallouj e Miles (2013), e também foi relatada em algumas entrevistas.

Eu cheguei em uma instituição em que os defensores de previdenciário, de ofício previdenciário, que estavam na ponta, tinham o INSS como inimigo número um, o INSS é o inimigo, eles que não atendem o nosso assistido e fazem essa enxurrada de demanda por direitos triviais dos assistidos em relação à aposentadoria, por exemplo. E aí, só que esse entendimento era um entendimento que não gerava ganho para o cidadão, eu acho. E aí uma das mudanças, como eu já tinha falado, o foco em soluções extrajudiciais é, vamos buscar o INSS para ver [...] (Entrevista 5).

Tem questões da Caixa Econômica, do INSS... A gente acaba interagindo com vários órgãos que geralmente são ligados ao Poder Judiciário. E todos acabam meio que se auxiliando a... prestação do serviço deles [...] (Entrevista 4).

Outra competência da DPU relaciona-se à realização de mutirões e busca ativa de cidadãos para a prestação de assistência. Uma ação citada recorrentemente nas entrevistas foi a itinerante, que consiste no deslocamento da estrutura do órgão para locais de difícil acesso ou habitados por grupos de pessoas específicos, incapacitados de buscar uma das sedes físicas da DPU, como se observa nos trechos a seguir. 
[...] projetos os especiais, provocando os defensores da ponta para participar dos itinerantes, que já existiam, do projeto quilombola, combate ao trabalho escravo [...] (Entrevista 5).

[...] o próprio itinerante, que a gente faz para conseguir chegar onde nossas sedes físicas não conseguem ser instaladas, a gente leva defensores de modo itinerante [...] (Entrevista 6).

Os conhecimentos e habilidades relacionados à promoção da conciliação extrajudicial consistem também em competência organizacional da DPU. A Lei Complementar no 80/1994 se refere a essa competência, ao declarar, em seu art. 4으, II, que é uma função institucional da Defensoria Pública a promoção da solução extrajudicial dos litígios, com o fito de pôr em acordo as pessoas em conflito de interesses, por meio de mediação, conciliação, arbitragem ou outras técnicas de composição de conflitos. Isso pôde ser observado em algumas entrevistas.

Acho que a gente pode dizer que nas questões ligadas à Previdência Social e à Caixa Econômica Federal, que os dois maiores litigantes da... com a Defensoria Pública da União, nós buscamos justamente essa resolução extrajudicial de conflitos [...] ( Entrevista 6).

Em suma, as principais competências organizacionais necessárias à prestação dos serviços de assistência jurídica referem-se a conhecimento e operação do Direito, atendimento ao público de modo transversal, interação com outros órgãos e entidades, capacidade de realização de mutirões de busca ativa de cidadãos, e conciliação extrajudicial de conflitos.

\section{Meios de entrega dos serviços}

Os meios de entrega dos serviços são as operações realizadas no momento da prestação. Tais operações podem ser materiais, informacionais, relacionais e de conhecimento, assim como os procedimentos científicos e tecnológicos a elas associados (DJELLAL; GALLOUJ, 2005).

Primeiro, as operações materiais são aquelas que envolvem a modificação de objetos tangíveis, tais como transporte, transformação, manutenção ou reparo desses materiais (DJelLAL; GallouJ, 2005). Ora, o serviço da DPU não evolve modificação de objetos tangíveis, desse modo, não é passível de possuir um meio de construção material.

As operações informacionais ou logísticas, por sua vez, são aquelas que envolvem a coleta e o processamento de informações codificadas, tais como produção, captura, transporte, arquivamento ou sua atualização (DJELLAL; GALLOUJ, 2005). 
Nesse sentido, os serviços prestados pela DPU são, em grande parte, construídos por meio dessas operações. Os órgãos de atuação da DPU são dotados de uma estrutura de cartório responsável pela distribuição, tramitação e arquivamento dos processos de assistência jurídica. Em resumo, o cidadão presta as informações aos agentes responsáveis pelo atendimento, que as reduzem a termo e as encaminham para o Cartório, o qual distribui os processos aos defensores, que decidirão o destino da demanda do cidadão.

As operações de conhecimento, por sua vez, envolvem o processamento intelectual do conhecimento, usando métodos codificados, rotinas e tecnologias intangíveis (DJellal; GallouJ, 2005). Na DPU, essas operações de conhecimento estão relacionadas à operação do Direito. As informações prestadas pelos cidadãos são codificadas pelos defensores públicos conforme seu conhecimento acerca da doutrina, normas, regulamentos, jurisprudência e matérias específicas do Direito. De fato, conforme é citado em uma das entrevistas, a Defensoria basicamente receberia as informações dos cidadãos e as codificaria para a linguagem jurídica.

É como se a Defensoria fosse um pouco isso, assim... fosse um hub que recebe as coisas, processa, e transforma na linguagem do interlocutor, e depois diz para a pessoa qual foi o resultado. É mais ou menos por aí [...] (Entrevista 3).

Já as operações relacionais são aquelas operações cujo principal meio é a interação com o usuário. Elas consistem no provimento do serviço diretamente em contato com o usuário, com maior ou menor grau de interação (DJELLAL; GALLOUJ, 2005). Na verdade, a interação defensor-cidadão na prestação dos serviços da DPU é bastante debilitada. Embora a DPU tenha se esforçado para criar canais de comunicação com o cidadão, essa interação escassa é inclusive foco de reclamação dos cidadãos, conforme destaca um dos participantes da pesquisa.

Esse serviço é um serviço, entre aspas, ontologicamente de advocacia, que guarda essa expectativa do assistido de ter o seu intuitu personae, de ter um contato com o defensor. Se carece muito, as muitas reclamações que chegam aqui são por conta, justamente, dele não ter esse contato com o defensor [...] (Entrevista 7).

\section{As inovações nos serviços prestados pela DPU}

A inovação, dependendo do tipo de modificação levada a cabo nas características do produto, pode tomar diversas formas. As formas de inovação listadas por Gallouj e Weinstein (1997) e adotadas no presente estudo para fins de identificação 
e classificação são as seguintes: radical, de melhoria, incremental, ad hoc, de formalização e por recombinação.

A inovação radical se dá por meio da criação de um novo serviço contendo características diferentes daqueles serviços anteriormente existentes (GALLOUJ; WeINSTEIN, 1997). No caso de entidades do Poder Público, a criação de novos serviços deve dar-se por meio de lei. Nesse sentido, a Lei Complementar no 132/2009, que alterou diversos dispositivos da Lei Complementar no 80/1994, instrumento que organiza a Defensoria Pública da União, trouxe uma inovação radical, o serviço de difusão e conscientização dos direitos humanos, da cidadania e do ordenamento jurídico.

No caso de inovação de formalização, não há variação nas características dos serviços, apenas a padronização de um sistema já existente (GALLOUJ; WEINSTEIN, 1997). Nesse sentido, quando perguntados sobre o assunto, apenas dois respondentes disseram haver padronização e citaram questões pontuais, como a instituição de atendimento por meio de plantões, ou questões não relacionadas à padronização dos serviços.

Há, contudo, a Resolução CSDPU no 60, de 2012, que dispõe sobre o atendimento ao público no âmbito da DPU. Por meio dessa resolução, são formalizadas diretrizes para as relações entre a DPU e os cidadãos; os direitos dos assistidos em relação ao atendimento da DPU são especificados claramente; assim como as atividades dos defensores responsáveis pelo atendimento ao público. Pode-se entender, portanto, que a Resolução CSDPU no 60, de 2012, é um esforço no sentido de padronização do sistema de serviços da DPU.

Além dessa resolução, a DPU conta com uma carta de serviços disponível em seu portal eletrônico (BRASIL, 2013). Nesse documento, são apresentadas informações sobre os serviços prestados pela DPU, o público-alvo desses serviços, o horário de atendimento, os requisitos e documentos necessários para o acesso ao serviço da DPU, os endereços e telefones dos órgãos de atuação da DPU em todo o País, as etapas para o processamento do serviço, a forma de prestação do serviço, os canais de comunicação com o assistido, bem como o prazo para a prestação do serviço. Nesse ponto, há uma mudança salutar, pois o órgão passa a se comprometer ao estabelecer prazo para o cumprimento de suas obrigações constitucionais.

A inovação de melhoria ocorre por meio da simples melhoria de certas características ou competências mobilizadas para a prestação do serviço (GALLOUJ; WEINSTEIN, 1997). Essa forma de inovação foi levada a cabo principalmente pelo desenvolvimento de sistemas informatizados relativos às operações informacionais. De fato, foi recorrente nas entrevistas a referência aos sistemas utilizados para o tráfego de informações na DPU. 
Como eu te falei, há um investimento muito claro para mim, nos últimos dois anos, também em tecnologia da informação. Então a rede interna da Defensoria Pública para o tráfego de dados, ou a comunicação entre as pessoas, isso acredito que tenha um impacto nos serviços. A própria reformulação do e-PAJ ${ }^{3}$, que está em andamento, está no período de teste, isso é o resultado de um investimento, e aí, eu acredito, de aporte orçamentário, dinheiro... e priorização da questão da TI para a melhoria dos serviços. Eu percebo isso (Entrevista 5).

Sim. A gente teve uma evolução do sistema informatizado que foi o e-PAJ. Está pra sair uma nova versão, mas evolui bem devagar. (Entrevista 4).

Em muitos dos serviços sim. Não em todos, mas em muitos sim. Eu acho que, fundamentalmente, numa que você participou, na questão do tempo de atendimento com o SGA. Isso foi fundamental, foi uma questão muito boa. Foi um ganho de tempo muito bom (Entrevista 1).

O Sistema de Gerenciamento de Processos de Assistência Jurídica (e-PAJ) é um sistema informatizado desenvolvido no âmbito da DPU e em funcionamento desde 2009, conforme Portaria DPGU no 155, de maio de 2009. Trata-se de uma solução tecnológica que auxilia na tramitação dos processos de assistência jurídica, ou seja, no compartilhamento de informações relativas aos serviços prestados aos cidadãos. Nesse sentido, o impacto dessa inovação se dá nas operações informacionais do serviço de assistência jurídica.

Outro sistema informatizado citado nas entrevistas é o Sistema de Gerenciamento do Atendimento (SGA). Ele auxilia o gerenciamento das filas e do fluxo de atendimento, possibilitando o planejamento, monitoramento, controle e otimização do atendimento ao cidadão. Esse sistema, que simplifica o procedimento de atendimento ao cidadão, é uma solução tecnológica advinda do Instituto Nacional do Serviço Social. O impacto dessa inovação está nas operações informacionais, no que se refere à sua faceta logística.

A inovação por recombinação ocorre por meio de novas combinações das características do serviço (GAllouj; Weinstein, 1997). Nesse caso, quando perguntados sobre o assunto, apenas um dos participantes respondeu positivamente e elaborou uma resposta evidenciando o fato.

Sim. Um exemplo que eu te daria para essa combinação seria o... olha só, vamos pegar aqui nossa atuação coletiva, a atuação individual e a atuação de orientação jurídica. É muito comum... vamos pegar o exemplo de benefícios

\footnotetext{
${ }^{3}$ Sistema de Gerenciamento de Processos de Assistência Jurídica
} 
previdenciários, direitos previdenciários e assistenciais... Então, assim, você pode requerer, vamos supor... aconteceu já, caso concreto... de o INSS começar a cobrar atrasados de assistidos que ganharam uma ação no primeiro grau e perderam no segundo grau. Então, ele teve aquele benefício de maneira precária durante algum momento, e o INSS começou a cobrar a devolução desses valores que foram recebidos de maneira provisória por força de alguma decisão judicial, que depois não foi confirmada... essa atuação começou a ser feita de maneira individual, ou seja, os assistidos, individualmente, começaram a procurar a Defensoria, o defensor público vislumbrou que a atuação do INSS não estava adequada ao direito e entrou com uma ação coletiva. Isso gerou também orientação jurídica, em forma de cartilhas e em forma de repercussão midiática. Ou seja, os próprios defensores, depois de ajuizar a ação coletiva, ele foi à mídia esclarecer à população de que não deveria se contentar com essa cobrança, que há solução jurídica e ele não deveria pagar, repetir esse dinheiro por força de um entendimento jurídico. Então, assim, a Defensoria tem uma força muito grande nesse sentido também. Então, às vezes, por um atendimento individual, que seria uma amostragem, que seria o método indutivo, você sai do caso particular e vai para o geral, então, usando até o método indutivo, você pega o caso concreto, transforma ele num caso coletivo e, caso ganhe uma liminar, você vai e divulga para a população e orienta juridicamente, e através até de cartilhas informativas. Então, eu acho que é um exemplo (Entrevista 7).

Em suma, o serviço que antes era prestado individualmente passou a ser prestado coletivamente. A possibilidade de impetração de ação civil pública é uma novidade trazida pela Lei Complementar no 132/2009. Trata-se de uma modificação nos meios de construção relacional e de conhecimento, ou metodológico. A operação relacional é modificada, pois a interação da DPU com o cidadão não se dá mais individualmente, passando a ser coletiva. Ao mesmo tempo, para que isso ocorra, as informações prestadas pelos cidadãos devem ser trabalhadas também coletivamente. Desse modo, é preciso que a DPU se utilize do método indutivo de construção do conhecimento para, a partir do caso concreto, formular uma tese jurídica que seja aplicável a todos os administrados.

Acerca da inovação incremental, apenas modificações marginais são levadas a cabo, por meio de adição ou substituição de elementos ao sistema de serviço. A estrutura geral do sistema permanece a mesma (GALlouj; WeINSTEIN, 1997). Um caso citado em uníssono por todos os participantes é a realização de eventos itinerantes para a busca ativa de assistidos, como exemplifica bem o trecho a seguir.

[...] além de ampliar o serviço da atividade fim, ela ampliou a sua área de atuação, na medida em que desenvolveu projetos especiais importantes, 
como o próprio itinerante, que a gente faz para conseguir chegar onde nossas sedes físicas não conseguem ser instaladas, a gente leva defensores de modo itinerante [...] (Entrevista 6).

Trata-se de uma inovação incremental, pois houve a adição de um novo elemento ao serviço, o deslocamento da estrutura da DPU até o local onde o cidadão necessitado se encontra. A interação entre Defensoria e cidadão se modifica, compreendendo, portanto, a adição de um elemento às operações relacionais.

Ademais, outra forma de inovação incremental levada a cabo por meio da adição de um elemento às operações relacionais é uma pesquisa de satisfação com o atendimento, elemento destacado por um dos participantes. Há ainda outros dois casos de inovação incremental que tratam da criação de canais de comunicação com o público alvo da DPU. Esses novos canais são basicamente programas de rádio e redes sociais. A criação desses canais de comunicação com o cidadão alcança diretamente as operações informacionais, uma vez que o objetivo desses novos elementos é levar informações sobre direito e cidadania à população. Tais inovações são destacadas nos trechos a seguir.

[...] A pesquisa de satisfação também. A gente não avaliava se tinha... como é que tinha sido prestado o serviço, e chegou a... e implementou o negócio para saber se tinha... se tinha prestado ou não para ele [...] (Entrevista 3)

Mais recentemente, no ano passado, a gente foi provocado em relação ao programa de rádio, e hoje a gente tem um programa de rádio que passa em 29 municípios onde tem DPU, contando que tem DPU em 64 municípios mais ou menos, 64 ou 67, eu não sei o número exato. Mas hoje o programa de rádio semanal voltado para serviços, ou seja, não tem agenda de defensor, tem o que a Defensoria faz em Direito Previdenciário, direito à saúde, direito à moradia, direitos coletivos... semanalmente, ele passa em 29 municípios do País que contam com Defensoria Pública da União, 9 deles no interior, 20... 9 deles capitais, 20 no interior. Passa também na Rádio Justiça, e são 36 rádios comunitárias em regiões de grande concentração do nosso público alvo, regiões mais pobres. Mais recentemente, a aceitação da rede social, no caso, a gente já estava no Twitter, mas no Facebook, de uma forma muito proativa e muito voltada para serviços. Mais uma vez, não entra a agenda do Defensor-Geral no Facebook, entra o "você sabe do seu direito em relação à aposentadoria especial? Sabe que documentos você tem que levar?" é isso que entra. Isso são grandes inovações (Entrevista 5).

A inovação ad hoc ocorre quando há construção de uma solução original para um problema particular de um dado usuário (GALLOUJ; WEINSTEIN, 1997). Essa forma de inovação foi citada de modo recorrente nas entrevistas, em consonância 
com Djellal, Gallouj e Miles (2013), que afirmam ser a inovação ad hoc o principal tipo de inovação em serviços intensivos em conhecimento. Ocorre que a DPU, ao identificar grupos de cidadãos em situações específicas, estabelece projetos especiais para a resolução de seus problemas.

Foram citados também projetos especiais que caracterizam inovações ad hocentre eles, o Grupo de Trabalho destinado à defesa das pessoas em situação de rua (GT - Rua), instituído por meio da Portaria DPGU no 42/2012 (e alterado por meio das Portarias DPGU no 527/2012, no 748/2013 e no 229/2014). Outros projetos especiais que caracterizam inovações ad hoc são aqueles voltados para grupos étnicos específicos, como é o caso de povos indígenas, comunidades quilombolas e ciganos. Nesse sentido, há uma série de normativos no órgão que comprovam a atuação da DPU junto a povos indígenas (Portarias DPGU no 120/2014 e no 177/2010, por exemplo) e a comunidades quilombolas (Portaria DPGU no 71/2014, por exemplo).

Nesse período que estou aqui, ela ${ }^{4}$ começou a abrir esses projetos do GT-RUA pra atender a assistidos em situação de vulnerabilidade social com relação a tóxicos e... questão de assistidos em situação de rua (Entrevista 1).

Um exemplo bom nesse caso aí seria a parceria que nós fizemos à época com a Sepir, que é a Secretaria Especial de Políticas de Igualdade Racial, e com a Fundação Cultural Palmares, que nós criamos treinamento, nas questões dos quilombolas e da igualdade racial, criamos treinamentos para os defensores através até da Escola Superior, na época, por um termo de cooperação. Nós criamos grupos específicos de defensores para lidar com as questões dos quilombolas, ou seja, hoje nós temos, para cada região do Brasil, defensores especializados na temática, e aí entra, nas questões dos quilombolas, igualdade racial, titulação... principalmente a titulação de terras para os quilombolas, que tem um procedimento especial, um decreto específico, uma lei específica. Então, esse é um exemplo que eu te dou de um projeto que foi criado especificamente para atender especificamente a população quilombola. Então, entra quilombolas, eu tenho casos para ciganos, população cigana, que vai nessa mesma linha, indígena, nós temos defensores hoje muito afetos à sistemática indígena, então, também nós temos uma tutela interessante para as comunidades tradicionais indígenas [...] (Entrevista 7).

Há também casos de inovação premiados, conforme cita o estudo técnico da DPU sobre seu panorama de atuação (BRASIL, 2014). Um deles é o serviço de

\footnotetext{
${ }^{4}$ A Defensoria Pública da União.
} 
assistência jurídica aos hansenianos no Estado do Maranhão, vencedor do Prêmio Innovare, edição de 2012, na categoria Defensoria Pública. Conforme a descrição da prática por Costa (2012), trata-se de solução específica ao problema do isolamento compulsório de pessoas acometidas pelo mal e internadas na Colônia do Bonfim, em São Luiz.

Outra prática premiada refere-se ao serviço de prevenção do escalpelamento (perda do todo ou de parte do couro cabeludo devido ao enroscamento dos cabelos da vítimas nas hélices dos motores dos barcos), vencedor da edição de 2010 do Prêmio Innovare, também na categoria Defensoria Pública. Conforme descrito por Oliveira (2010), o serviço se dá por meio de orientação das vítimas sobre direitos e orientação da população ribeirinha acerca dos modelos de cobertura das hélices do barco, visando à prevenção de acidentes.

\section{Princípios norteadores da inovação}

No tocante aos princípios norteadores, ou organizadores, das inovações, há quatro tipos propostos por Djellal e Gallouj (2005). Primeiro, quando novos serviços constituintes são adicionados ao principal, o princípio norteador da inovação atuante é o extensivo. De modo contrário, o princípio regressivo envolve a eliminação de serviços constituintes. Há ainda o princípio organizador intensivo, que se dá por meio de mudanças nos componentes internos ou externos do produto final. Por fim, o princípio organizador combinatório age quando diversas características são combinadas para a constituição de novos serviços (DJELLAL; GALLOUJ, 2005).

Sobre o princípio extensivo, dos quatro serviços constituintes elencados para a DPU - orientação jurídica, defesa nas esferas judicial e administrativa, difusão de conhecimentos e resolução de conflitos -, apenas um é novidade no ordenamento jurídico. Trata-se da difusão e conscientização dos direitos humanos, da cidadania e do ordenamento jurídico, conforme inciso III, do art. 4으, da Lei Complementar no 80/1994, cuja redação foi dada pela Lei Complementar no 132/2009. Observa-se, portanto, que esse princípio orientou a inovação radical.

Acerca da eliminação de serviços constituintes, princípio regressivo, dois dos respondentes lembraram-se da restrição de atendimentos na área trabalhista. Inicialmente, a DPU implantou projetos-piloto para identificar a possibilidade de atendimentos nessa área do Direito em todo o País; no entanto, percebeu que a demanda é bem superior à sua capacidade instalada e retrocedeu. Não se trata, no entanto, de eliminação de um serviço constituinte, uma vez que a defesa judicial continua sendo prestada nas outras áreas do Direito, mas apenas da eliminação de um meio de conhecimento para a construção do serviço. 
Tem um exemplo de serviço que deixou de ser prestado, que foi a assistência trabalhista em Brasília, que foi restringida. Foi criado um projetopiloto para atuação na esfera trabalhista aqui em Brasília, por que a gente tem atribuição para atuar no trabalhista, só que é um mundo que a gente ainda não conhece, que não atua efetivamente. Então, eram quatro ofícios e esse grupo não daria conta de todos que procuravam. Daí, passou a limitar apenas para as domésticas, como uma forma de limitar para um tipo de serviço, que é um novo... pequeno retrocesso, mas por que não havia possibilidade de dar conta daquela área. O serviço estava inviável (Entrevista 4).

A inovação orientada pelo princípio intensivo pode ocorrer pela adição de novas competências ou tecnologias, por sua redução ou pela transformação de competências ou tecnologias existentes em elementos mais significativos. 0 modelo intensivo de inovação segue distintas trajetórias para qualquer serviço constituinte, a saber: trajetória de transformação logística e material; trajetória de processamento logístico e informacional; trajetória metodológica e cognitiva; e trajetória relacional (DJELLAL; GALLOUJ, 2005).

De todas as inovações listadas na seção anterior, aquelas relacionadas às formas de inovação incremental e de melhoria estão relacionadas ao princípio intensivo. Desse modo, entende-se que esse princípio é o principal norteador das inovações na DPU. A implantação de soluções tecnológicas para o tráfego de informações e para a organização das filas nos órgãos de atuação da DPU é orientada pelo princípio intensivo, pois tais inovações se deram por meio da adição de tecnologias aos meios de entrega informacional e logístico. Do mesmo modo, a criação de canais de comunicação com o público da DPU, tais como o programa de rádio e os perfis do órgão nas redes sociais, acrescenta elementos novos ao meio de construção informacional. Ou seja, trata-se de uma melhora nos sistemas de informação e comunicação, referindo-se, portanto, à trajetória de processamento logístico e informacional.

É possível considerar também que a realização de eventos itinerantes e a pesquisa de satisfação sejam guiadas pelo princípio intensivo. De fato, tais inovações no serviço da DPU atingem o meio de construção relacional, tornando-o mais significativo, referindo-se, por conseguinte, à trajetória relacional.

O princípio combinatório também atuou no direcionamento das inovações nos serviços da DPU. As inovações do tipo ad hoc e recombinação foram orientadas principalmente por esse princípio. Primeiro, a atuação da DPU na defesa coletiva dos interesses dos cidadãos realizou-se com base nesse princípio. De fato, ocorreu uma combinação entre os meios de construção relacional e de conhecimento, uma vez que a interação da Defensoria com os usuários de seus serviços passou 
a acontecer na esfera coletiva e, ao mesmo tempo, os conhecimentos e técnicas utilizadas na construção do serviço se ampliaram.

Depois, pode-se considerar que os projetos especiais, referentes a soluções para grupos de cidadãos específicos, também foram orientados pelo princípio combinatório. A combinação se deu entre os meios de construção do serviço relacional, uma vez que a forma de interação com o assistido foi modificada, e de conhecimento, pois passou a ser necessário o domínio de técnicas e conhecimentos específicos para lidar com as idiossincrasias dos grupos em situação de vulnerabilidade social.

Por conseguinte, a abordagem integradora permite a percepção de inovação no serviço público de assistência jurídica. Com efeito, organizações do setor público já não são adotantes passivas de tecnologias produzidas em outros lugares. Conforme se observa no caso da Defensoria Pública da União, esse tipo de organização é capaz de produzir suas técnicas autonomamente e orientar a inovação em seus serviços (DJellal; Gallouj; Miles, 2013).

\section{Conclusões e recomendações}

O objetivo geral do presente trabalho foi o de identificar as características dos serviços da DPU, sob a ótica da abordagem integradora da inovação. Para atingir esse objetivo, foi preciso identificar os serviços principais e os constituintes da DPU, assim como as características desses serviços, além de identificar as inovações levadas a cabo nos serviços prestados por esse órgão.

Evidenciou-se que o principal serviço da Defensoria é a prestação de assistência jurídica às pessoas necessitadas. Ele pode ser dividido nos serviços constituintes de orientação jurídica, defesa nas esferas judicial e administrativa, difusão de conhecimentos sobre direitos, e resolução de conflitos por meio de conciliação.

Acerca das características dos serviços, ressalta-se que elas foram divididas em competências organizacionais e meios de entrega. As competências que a Defensoria mobiliza estão relacionadas ao conhecimento e operação do Direito, atendimento ao público de forma transversal, ou interdisciplinar, interação com outros órgãos e entidades, capacidade de realização de mutirões de busca ativa de cidadãos, bem como composição extrajudicial de conflitos. Já no que se refere aos meios de entrega, eles envolvem operações informacionais, operações de conhecimento ou metodológicas, e operações relacionais. As operações informacionais levadas a cabo na DPU abrangem o recebimento, distribuição, tramitação e arquivamento das informações prestadas pelo cidadão. As operações de conhecimento abarcam o tratamento das informações prestadas pelo cidadão e sua codificação para a linguagem jurídica. As operações relacionais, por sua vez, envolvem a interação defensor-cidadão baseada, na maior parte dos casos, na prestação de informações. 
Sobre as inovações nos serviços prestados pela DPU, o único serviço novo foi o de difusão de conhecimentos. No entanto, observou-se uma série de inovações nas características dos serviços existentes. Tais inovações se deram com base na modificação de elementos relacionados aos meios de construção informacional, relacional e de conhecimento, com especial atenção aos dois primeiros.

Entre os princípios norteadores, o que mais influenciou o processo de inovação nos serviços da DPU foi o intensivo. Sua ocorrência está relacionada às formas de inovação incremental e de melhoria. Isso se deve ao fato de o princípio intensivo organizar a inovação por meio da adição de novas competências ou tecnologias, por sua redução ou pela transformação de competências ou tecnologias existentes em elementos mais significativos.

Ademais, o princípio norteador intensivo segue, na DPU, as trajetórias relacional e de processamento logístico e informacional. A trajetória relacional está ligada a modificações nos meios de entrega dos serviços que envolvem o relacionamento com o usuário. Já a trajetória de processamento logístico e informacional está ligada a modificações nos meios de entrega relativos ao recebimento, distribuição, tramitação e arquivamento das informações prestadas pelo cidadão. Em suma, as inovações levadas a cabo na DPU buscam aprimorar o relacionamento com os cidadãos e a obtenção de informações.

No entanto, apesar de terem sido observados diversos casos de inovação nos serviços da Defensoria e de se ter conseguido listar uma série de características desses serviços, os resultados guardam o viés dos gestores da DPU. Ou seja, não se buscou, neste estudo, o ponto de vista do usuário do serviço de assistência jurídica, o que pode ser realizado em pesquisas futuras. Seria interessante entender a percepção do cidadão acerca da inovação nos serviços de assistência jurídica e compará-la com a percepção dos gestores de órgãos que prestem esses serviços.

Outros problemas passíveis de serem estudados futuramente seriam a relação entre as atividades do Sistema de Justiça e a inovação nos serviços públicos levados a cabo no âmbito dos demais Poderes. Nesse sentido, as organizações do Sistema de Justiça seriam realmente capazes de induzir o Estado a prestar serviços mais efetivos? A atuação dessas organizações poderia gerar mais valor para os serviços ofertados pelo Estado? As ações das organizações do Sistema de Justiça são capazes de induzir inovações nos serviços públicos?

Por fim, um dos possíveis benefícios desta pesquisa é seu emprego como âncora para estudos futuros sobre a inovação nos serviços públicos. Ademais, o contexto de atuação da DPU pode ser um indutor de inovações em outros órgãos públicos, ou seja, existe a possibilidade de sua interação com os demais órgãos e entidades do poder público ser um fator facilitador de melhorias nos serviços públicos. 


\section{Referências bibliográficas}

Bandeira de Mello, C. A. Curso de Direito Administrativo. 23. ed. São Paulo: Malheiros, 2007.

BARDIN, L. Análise de conteúdo. São Paulo: Edições 70, 2011.

BRANDÃo, S. M.; BRUNO-FARIA, M. F. Inovação no setor público: análise da produção científica em periódicos nacionais e internacionais da área de administração. Revista de Administração Pública, Rio de Janeiro, 47(1), p. 227-248, jan./fev. 2013.

BrASIL. Constituição da República Federativa do Brasil de 1988. Brasília: Presidência da República. Disponível em: http://www.planalto.gov.br. Acesso em: 16.4.2014.

Defensoria Pública da União. Portaria DPGU no 155, de 12 de maio de 2009. Designa Comitê Gestor para a implantação do novo Sistema de Gerenciamento de Processos de Assistência Jurídica - e-PAJ. Disponível em: http://www.dpu.gov.br. Acesso em: 18.6.2014.

Defensoria Pública da União. Portaria DPGU no 177, de 16 de abril de 2010. Delegar competência ao Defensor Público-Chefe da Defensoria Pública da União no Estado do Amazonas para assinar Acordo de Cooperação com a Secretaria Estadual Para os Povos Indígenas - SEIND. Disponível em: http://www.dpu.gov.br. Acesso em: 18.6.2014.

Defensoria Pública da União. Portaria DPGU no 42, de 24 de janeiro de 2012. Institui o Grupo de Trabalho destinado à defesa dos direitos das pessoas em situação de rua (GT-RUA). Disponível em: http://www.dpu.gov.br. Acesso em: 18.6.2014.

Defensoria Pública da União. Portaria DPGU no 527, de 30 de agosto de 2012. Prorroga as atividades do Grupo de Trabalho destinado à defesa dos direitos das pessoas em situação de rua (GT-RUA). Disponível em: http://www.dpu. gov.br. Acesso em: 18.6.2014.

Defensoria Pública da União. Portaria DPGU no 748, de 20 de setembro de 2013. Prorroga as atividades do Grupo de Trabalho destinado à defesa dos direitos das pessoas em situação de rua (GT-RUA). Disponível em: http://www. dpu.gov.br. Acesso em: 18.6.2014.

Defensoria Pública da União. Portaria DPGU no 71, de 11 de fevereiro de 2014. Institui o Grupo de Trabalho para acompanhamento e divulgação das demandas apresentadas à Defensoria Pública da União pelas comunidades quilombolas tradicionais, nos termos da Carta de Cuiabá. Disponível em: http:// www.dpu.gov.br. Acesso em: 18.6.2014.

Defensoria Pública da União. Portaria DPGU no 88, de 14 de fevereiro de 2014. Dispõe sobre o Regimento Interno da Defensoria Pública-Geral da União. Diário Oficial da União, seção 1, de 18.2.1014. p. 73-81.

Defensoria Pública da União. Portaria DPGU no 120, de 5 de março de 2014. Designa Defensor Público Federal para atuação em projeto de atendimento de comunidades indígenas no Estado do Rio de Janeiro. Disponível em: http://www. dpu.gov.br. Acesso em: 18.6.2014. 
Defensoria Pública da União. Portaria DPGU no 229, de 19 de maio de 2014. Altera a Portaria DPGU no 748, de 20 de setembro de 2013. Disponível em: http://www.dpu.gov.br. Acesso em: 18.6.2014.

Defensoria Pública da União. Resolução CSDPU no 60, de 9 de maio de 2012. Dispõe sobre o atendimento ao público e dá outras providências. Disponível em: http://www.dpu.gov.br. Acesso em: 18.6.2014.

Defensoria Pública da União. Resolução CSDPU no 85, de 11 de fevereiro de 2014. Fixa parâmetros objetivos e procedimentos para a presunção e comprovação da necessidade das pessoas naturais e jurídicas. Disponível em: http://www.dpu.gov.br. Acesso em: 18.6.2014.

Defensoria Pública da União. Carta de Serviços. Brasília: DPU, 2013. Disponível em: http://www.dpu.gov.br. Acesso em: 15.6.2014.

Defensoria Pública da União. Assistência jurídica integral e gratuita no Brasil: um panorama da atuação da Defensoria Pública da União / Defensoria Pública da União. Brasília: DPU, 2014. 76 p.: il. (Série Estudos Técnicos da DPU; 01). Disponível em: http://www.dpu.gov.br. Acesso em: 18.6.2014.

Defensoria Pública da União. Rádio. Disponível em: http://www.dpu. gov.br. Acesso em: 18.06.2014.

Emenda Constitucional $\mathrm{n}$-45, de dezembro de 2004. Altera dispositivos dos arts. 5ㅇ, 36, 52, 92, 93, 95, 98, 99, 102, 103, 104, 105, 107, 109, 111, 112, 114, $115,125,126,127,128,129,134$ e 168 da Constituição Federal, e acrescenta os artigos 103-A, 103B, 111-A e 130-A, e dá outras providências. Brasília: Presidência da República. Disponível em: http://www.planalto.gov.br. Acesso em: 16.4.2014.

Emenda Constitucional no 74, de agosto de 2013. Altera o art. 134 da Constituição Federal. Brasília: Presidência da República. Disponível em: http:// www.planalto.gov.br. Acesso em: 16.4.2014.

Emenda Constitucional no 80, de 4 de junho de 2014. Altera o Capítulo IV - Das Funções Essenciais à Justiça, do Título IV - Da Organização dos Poderes, e acrescenta artigo ao Ato das Disposições Constitucionais Transitórias da Constituição Federal. Disponível em: http://www.planalto.gov.br. Acesso em: 18.6.2014.

Lei Complementar no 80, de 12 de janeiro de 1994. Organiza a Defensoria Pública da União, do Distrito Federal e dos Territórios e prescreve normas gerais para sua organização nos Estados, e dá outras providências. Diário Oficial da União, Brasília, seção 1, de 13.1.1994. p. 1-11.

Lei Complementar $n$ ㅇ 132, de 7 de outubro de 2009. Altera dispositivos da Lei Complementar no 80, de 12 de janeiro de 1994, que organiza a Defensoria Pública da União, do Distrito Federal e dos Territórios e prescreve normas gerais para sua organização nos Estados, e da Lei no 1.060, de 5 de fevereiro de 1950, e dá outras providências. Diário Oficial da União, Brasília, seção 1, de 8.10.2009, p. 1-4.

Pacto de Estado em Favor de um Judiciário Mais Rápido e Republicano. Diário Oficial da União, n. 241, seção 1, p. 8-9, 16 de dezembro de 2004. 
II Pacto Republicano de Estado por um Sistema de Justiça Mais Acessível, Ágil e Efetivo. Diário Oficial da União, n. 98, seção 1, p. 1-2, 26 de maio de 2009.

CostA, Y. M. P. Assistência a atingidos pela hanseníase no Maranhão. Instituto Innovare, 2012. Disponível em: http://www.premioinnovare.com.br. Acesso em: 18.6.2014.

D'Araujo, M. C. Democracia e novas institucionalidades jurídicas na América Latina. Revista de Administração Pública, v. 31, n. 1, p. 145-166, 2001.

Dı PIetro, M. S. Z. Direito Administrativo. 23. ed. São Paulo: Atlas. v. 1, 2010.

DJellat, F.; Gallouj, F. Mapping innovation dynamics in hospitals. Research Policy, v. 34, p. 817-835, 2005.

DJellat, F.; GallouJ, F.; Miles, I. Two decades of research on innovation in services: which place for public services? Structural Change and Economic Dynamics, v. 27, December, p. 98-117, 2013.

FoWler, F. Pesquisa de Levantamento. Porto Alegre: Penso, 2011.

GADREY, J. The characterization of goods and services: an alternative approach. Review of Income and Wealth, Series 46, n. 3, 2000.

Gallou, F.; SAvonA, M. Innovation in Services: a review of the debate and research agenda. Journal of Evolutionary Economics, n. 19, p. 149-172, 2009.

GallouJ, F.; WeInSteIn, O. Innovation in services. Research Policy, n. 26, p. 537-556, 1997.

HILL, T. P. On Goods and Services. The Review of Income and Wealth, 4, p. 315-338, 1977.

HALVORSEN, T. On innovation in the public sector. In: HALVORSEN, T., HAUKNES, J.; MILES, I.; Roste, R. Innovation in the Public Sector. Publin Report no D9. NIFU STEP, Oslo, 2005.

ISIDRo-FIlho, A. S.; GUimarÃes, T. A.; PeRIN, M. G. Determinants of innovations in information and communication technologies adopted by hospitals. Revista de Administração e Inovação, v. 8, p. 142-159, 2012.

MACIEL, D. A.; Koerner, A. Sentidos da judicialização da política: duas análises. Revista Lua Nova, n. 57, p.113-133, 2002.

MADEIRA, L. M.. Institutionalisation, reform and independence of the Public Defender's Office in Brazil. Brazilian Political Science Review, p. 47-78, 2014.

OLIVEIRA, L. S. Erradicação do escalpelamento: justiça para a população invisível. Instituto Innovare, 2010. Disponível em: http://www.premioinnovare.com.br. Acesso em: 18.6.2014.

Resende JR., P. C.; GuimarÃes, T. A.; Bilhim, J. A. F. Escala de orientação para inovação em organizações públicas: estudo exploratório e confirmatório no Brasil e em Portugal. Revista de Administração e Inovação, v. 10, p. 257-277, 2013.

SOUSA, M. M.; GUIMARÃES, T. A. Inovação e desempenho na administração judicial: desvendando lacunas conceituais e metodológicas. Revista de Administração e Inovação, v.11, p. 321-344, 2014. 
Bernardo Oliveira Buta

Mestre em Administração (2016), Bacharel em Gestão de Políticas Públicas (2014) e em Ciências Biológicas (2007), todos pela Universidade de Brasília. Atualmente, atua como Assessor-Chefe de Planejamento, Estratégia e Modernização da Gestão da Defensoria Pública-Geral da União. Contato: bernardo.buta@gmail.com

Antonio Isidro Silva Filho

Doutor (2010) e Mestre (2006) em Administração, formado pela Universidade de Brasília, MBA em Gestão de Pessoas pela Fundação Getúlio Vargas (2004) e Psicólogo formado pelo Centro Universitário de Brasília (2002). Formação em Gestão pela École des Hautes Études Commerciales (HEC/Université de Montréal/Canadá, 2005). Professor Adjunto na Universidade de Brasília, Professor e Pesquisador no Departamento de Administração (ADM/ UnB) e no Programa de Pós-Graduação em Administração (PPGA/UnB). Coordenador do Núcleo de Estudos e Pesquisas em Inovação e Estratégia (NINE) da UnB. Coordenador do Mestrado Profissional em Administração Pública (MPA/PPGA/UnB). Contato: antonio.isidro.filho@gmail.com 
RSP 